\title{
28 Research Soure \\ Reinforcement of RNA interference by gut bacteria in a leaf beetle
}

\section{Letian Xu}

Shijing Xu

Liuwei Sun

Yiqiu Zhang

Jing Luo

Ralph Bock

Jiang Zhang

\section{Video Byte}

Keywords: gut bacteria, RNA interference, double-stranded RNA, leaf beetle, synergism, microbiota, Microbiome, pest control, insect control, pest management, insect management, RNAi, environmental RNAi, dsRNA, Plagiodera versicolora, Pseudomonas putida, pesticide, insecticide, Coleoptera, coleopteran, leaf beetle, willow leaf beetle

Posted Date: October 16th, 2021

DOI: https://doi.org/10.21203/rs.3.rs-979302/v1

License: (c) (i) This work is licensed under a Creative Commons Attribution 4.0 International License. Read Full License 


\section{Abstract}

RNA interference (RNAi), a popular technique for gene silencing using double-stranded RNAs (dsRNAs), can be used to manage insect pests. Once eaten by insects, the dsRNAs target specific genes to reduce growth or cause death. Multiple factors affect RNAi efficiency, but it's unknown if the gut microbiota, which encounters the ingested dsRNAs in the gastrointestinal tract, is a factor. A recent study investigated the effects of RNAi on a major tree pest, the willow leaf beetle, and explored the influence of the microbiome with molecular biology techniques. The ingested targeted dsRNAs were highly lethal to nonaxenic beetles (with gut microbes) but were less lethal to axenic (microbe-free) beetles despite equivalent gene-silencing effects. All dsRNAs altered the microbiota composition and induced overgrowth of gut bacteria, especially Enterobacter and Pseudomonas, perhaps in part because their degradation provided food for the bacteria. The targeted dsRNAs also changed the gut structure, allowing bacteria to enter the hemocoel. One isolated bacterium, Pseudomonas putida, was particularly effective in accelerating dsRNA-mediated mortality when reintroduced. Although further studies are needed to determine the exact gut dysbiosis-inducing mechanisms, the findings reveal a synergistic role of the microbiome in RNAibased pest control that may be useful for refining this insect management strategy. 